\title{
Origin and complete breed standard of Maltese Black breed
}

\author{
G. ATTARD ${ }^{1}$, P. AQUILINA ${ }^{1}$, S. CECCOBELLI ${ }^{2}$, R. RIDLER ${ }^{3}$, C. CASTELLINI ${ }^{2}$ \\ and E. LASAGNA ${ }^{2 *}$ \\ ${ }^{1}$ Institute of Earth Systems, University of Malta, Malta; ${ }^{2}$ Department of Applied \\ Biology, University of Perugia, Italia; ${ }^{3}$ Maple Stone farm, Garafraxa, Ontario, \\ Canada \\ *Corresponding author: emiliano.lasagna@unipg.it
}

This review is a first attempt to give a comprehensive historical account on the evolution of the Maltese Black chicken breed. The initiative consolidates available information to propose hypothesis on the origins of the breed, and to develop a comprehensive breed standard in conformity with the format of the American Breed Standard. The Maltese Black was established in 1950 as a rustic, dual purpose breed capable of producing adequate egg and chicken for consumption. In the 1960's, it was replaced with commercially available stock, marginalising the breed and restricting its existence to small dispersed populations. An initial attempt to have an in-situ conservation of the Maltese Black started in 1998 with a small flock of about 400 chickens that were later relocated to the Agricultural Research and Development Centre in Malta with the intention of maintaining a nucleus flock as a measure for a long term ex-situ conservation strategy. A recent survey highlights that the present population has drifted significantly away from standards first published in 1950. In efforts to consolidate the breed standard definition of the Maltese Black, the breed standards of related Mediterranean breeds, as confirmed by molecular markers, were consulted to translate and address the missing gaps in the previous breed standards. The updated breed standard presented will act as the bench mark against which all future breeding and selection programs are compared.

Keywords: Maltese Black; local breed; chicken; biodiversity

\section{Introduction}

Maltese popular culture describes a black feathered chicken as being indigenous. Mallia (1998) claims that the Maltese Black may represent a relict population of relatively unselected breed that were formerly characteristic of the Mediterranean, and furthermore he claims that documentation describing the breed is not available. A small population is still present and is utilised exclusively for show purposes. With

(C) World's Poultry Science Association 2014

World's Poultry Science Journal, Vol. 70, June 2014

Received for publication June 18, 2013

Accepted for publication January 8, 2014 
the lack of breed standard awareness, breeders and poultry judges have had a free hand at interpreting the breed's characteristics and phenotype. Nonetheless, this breed is widely known as non-sitting, with excellent egg laying potentials, both characteristics typical of Mediterranean breeds. Anderson (1802), Borg (1933), Brockman (1961) and Mallia (1998) all state that additionally the breed has acceptable carcass qualities.

The Secretaries of Agriculture of the European Union (EU) passed a directive in June 1999 prohibiting the use of conventional layer cage in all EU member states as from January 1st, 2012. A form of extensive poultry production systems (Organic poultry production) is governed by EU Council Regulation 1804/1999 which has the status of a law. Annex 1 section 3.1 of this regulation stipulates that:

1) the choice of breed or strain of bird must consider the capacity to adapt to extensive rearing conditions, vitality and resistance to disease;

2) preference should be given to indigenous breeds or strains.

Large animal production under the organic certification program in Malta is severely challenged due to the scarcity of available land base, the average farm size being only 0.8 hectare. Given this limitation of the Maltese territory, poultry represent most probably the only form of organic livestock production possible.

Mallia (1998; 1999) describes the first attempt to have an in-situ conservation of the Maltese Black. The small nucleus flock consisting of three lines with a total population of about 400 chickens was relocated to the Agricultural Research and Development Centre (Ghammieri, Malta) to maintain a protected genetic pool as a measure for future long term ex-situ conservation strategy. Due to the lack of appropriate resources and knowhow required to manage such projects the progress achieved is very limited and has, over the years, served mainly as a source for the procurement of genetic stock to amateur breeders. The lack of a defined breed standard has further hindered any attempt for objective breeding, multiplication and selection. In addition, the United Nations' Food and Agriculture Organisation (2009) supports initiatives for the preservation of local and indigenous genotypes and safeguarding farm animal biodiversity.

The aim of this paper is to retrieve, analyse and combine information to propose a hypothesis on the origins of the breed, and to develop a comprehensive standard for the Maltese Black that conforms with the format of the American Breed Standard.

\section{Historical background of the poultry industry in Malta}

Various reports indicate that, prior to the 1960 's, the Maltese poultry industry was unstructured and influenced by various historical issues. Having been part of the Spanish Empire in 1479 and later, in 1530, handed to the Knights of Saint John, Malta established strong cultural and commercial links with Spain, Portugal and Italy to the extent that livestock from these countries including poultry could have landed into Malta, a hypothesis supported by Mallia (1998). Ireland H. William (1828) states that, towards the conclusion of the siege of Malta during the French era (1798-1800), all livestock had been consumed and animal populations dwindled to very low numbers, and poultry was no exception. It is not clear if the drastic fall in livestock numbers was concentrated in centres where the French forces were stationed or if it was wide spread all over the rest of the islands. The fact that Anderson (1802) described the rearing of poultry as being wide spread among the middle and lower social classes tends to suggest that the country side may have been spared from the drastic decline in farm animals.

With the arrival of the British forces in the early 1800's, and the utilisation of the island as a military and maritime hub, it would be appropriate to assume that there was not 
enough locally produced chicken and eggs to meet market demands for consumption. Patrick's (1975) reference to the importation of 'Barbary Hens' is supported by Cornell (1857), who stated that cattle, sheep, and poultry were exported from Tripoli to Malta.

During the peak of poultry mania in Britain and, more specifically, post 1850's until 1930 's, the Maltese poultry sector may have shared the same enthusiasm and absorbed imports of various types of exotic fowl. Azzopardi (1933) reported that live poultry together with hatching eggs were imported from England, America and Australia, and hence the local population of chicken at that time was a random concoction of predominantly mixed Mediterranean breeds, and no true Maltese Breed was present. On the other hand, Borg (1933), while insisting that a Maltese breed having phenotypical resemblance to the Minorcan does exist, supports the fact that the pure form had been diluted due to cross breeding, in particular with the Leghorn, Livorno and the Langshan breeds. Shepard (1920) proposed that the poultry populations were of mixed character, but perhaps retaining affinities with the Minorcan and the Leghorn breeds. The existence of Andalusian and Black Leghorn parentage was further supported by Patrick (1975). Out of all the breeds mentioned, the Langshan was viewed as a problem (Borg, 1933) and held responsible for negatively influencing the production potential of the local flock and for impregnating brown taint onto the egg shells.

A Government of Malta report (Government Departments Report, 1933-1934) indicated that, in 1933, attempts to create a Maltese breed was undertaken. A nucleus flock consisting of entirely black feathered chickens was obtained from various sources from all over the islands. The program was continued over several generations at the Government experimental farm, and a multiplication and selection breeding programme was implemented until the desired phenotypic traits were fixed and bred true.

\section{The origins of the Maltese Black breed}

These historical reports conflict with the hypothesis proposed by Mallia (1998) that the Maltese population of black poultry represent a relict population of relatively unselected poultry that were formerly characteristic of the Mediterranean. The mongrel nature of the local population is supported by the fact that, on breeding the unselected phenotypically black chicken, the offspring were of different size, colour and form. Cesareo (1950), states that the Maltese Black originated in 1934 from the Maltese Department of Agriculture using locally available indigenous stock comprising of 40 hens and 3 cockerels, and all were '...mongrels and were gathered from several farms irrespective of any type and conformation, but all of one colour, that is black feathers...'. On hatching, progeny from these all black parents were all colours including black and brown, brown, brown and white and Andalusian colours. Some chicks had tufts of white feathers on their heads like Polish and Houdan breeds. The expression of these different phenotypes agrees with Azzopardi (1933) and confirms the introduction of different fowl into the gene pool.

Following multiplication to maximise genetic expression, a selection procedure was undertaken to standardise and define the breed. The best cockerels and pullets hatched from preferred hens were selected as parents for the next generation. Selection was continued for four consecutive years during which the birds gradually and steadily improved in colour and type. Egg production increased from 120 to 170 per year, with exceptional families producing over 200 eggs per year. In 1938, the prolificacy of this breed was already recognised and documented by the Commonwealth Bureau of Animal Breeding and Genetics, which stated that 'As regards fertility in poultry, the 
Maltese Black proved to be superior to imported breeds, Rhode Island Reds being next in merit'. In 1939, Minorcan eggs were imported and the hatched chickens were introduced into the genetic pool to improve feather colour, whitening of the earlobe and egg size. Minorcan blood was reintroduced again in 1948.

Contrary to Mallia (1998), who asserts that no written record or descriptions of the breed are available, the University of Hawaii (1945) quotes a communication in which the results of a comparative study carried over several years involving three imported breeds were compared with native stock of Maltese Black; and the breed standard was presented to both a local and international audience in 1950 in two separate publications, summarised in Table 1. For all intents and purposes, the Maltese Black breed was deemed to have been fixed as a specific breed in 1950 with the publication of the standards by Cesareo (1950), which is further supported by an article 'New Breed Developed' published in 1951 in the March issue of Poultry Digest.

Table 1 Published standards for the Maltese Black breed.

\begin{tabular}{|c|c|c|c|}
\hline $\begin{array}{l}\text { Morphological } \\
\text { traits }\end{array}$ & Cesareo (1950) & Il-Bidwi (1950) & Mallia (1999) \\
\hline Head & & Neat appearance (male) & \\
\hline Neck & & $\begin{array}{l}\text { Long and full with long neck } \\
\text { hackles }\end{array}$ & \\
\hline Body & & $\begin{array}{l}\text { Wide shoulders, long back slightly } \\
\text { inclined towards the tail. Long } \\
\text { wings with wide primary feathers } \\
\text { which are tightly capped to the side }\end{array}$ & \\
\hline Carriage & & Erect, alert and proud (male) & \\
\hline Plumage & $\begin{array}{l}\text { Absolute black } \\
\text { feathers with a } \\
\text { green sheen on both } \\
\text { male and female }\end{array}$ & $\begin{array}{l}\text { Smooth like silk, but not 'silky', } \\
\text { and not very overcrowded. Glossy } \\
\text { black feathers with a green sheen }\end{array}$ & $\begin{array}{l}\text { Close fitting, black, with a } \\
\text { green sheen in males, } \\
\text { localised to the tail coverts }\end{array}$ \\
\hline $\begin{array}{l}\text { Under colour of } \\
\text { feather }\end{array}$ & Pure black & & \\
\hline Skin & & & White \\
\hline Comb male & $\begin{array}{l}\text { Straight, large with } \\
\text { five serrations }\end{array}$ & $\begin{array}{l}\text { Single, straight with five deep } \\
\text { serrations of the same size which } \\
\text { are at the base. Blade does not } \\
\text { touch the head, without 'thumb } \\
\text { marks' and 'side sprigs' }\end{array}$ & $\begin{array}{l}\text { Single, with four or five } \\
\text { points and upright }\end{array}$ \\
\hline $\begin{array}{l}\text { Comb male } \\
\text { height }\end{array}$ & & & $4.1 \mathrm{~cm}$ \\
\hline Comb female & $\begin{array}{l}\text { Comb falls on one } \\
\text { side, but not to } \\
\text { obstruct the eye }\end{array}$ & $\begin{array}{l}\text { Nicely folded to the side without } \\
\text { obstructing the eye but similar to } \\
\text { the cock's }\end{array}$ & $\begin{array}{l}\text { Bright red, smooth textured } \\
\text { and folded over to one side } \\
\text { without obstructing the eye }\end{array}$ \\
\hline $\begin{array}{l}\text { Comb female } \\
\text { height }\end{array}$ & & & $2.4 \mathrm{~cm}$ \\
\hline Face and & & Smooth face. Long and slim & \\
\hline Wattles & & wattles, both bright red & \\
\hline Beak & & $\begin{array}{l}\text { Strong with tip exceeding the comb, } \\
\text { slate colour }\end{array}$ & Slate and horn in colour \\
\hline Eyes & $\begin{array}{l}\text { Large and } \\
\text { prominent }\end{array}$ & Large and amber & Amber and prominent \\
\hline Earlobes & $\begin{array}{l}\text { Round, white } \\
\text { smooth free from } \\
\text { folds }\end{array}$ & $\begin{array}{l}\text { Large smooth earlobes without } \\
\text { folds, chalk white }\end{array}$ & $\begin{array}{l}\text { White and with a single, } \\
\text { central, longitudinal } \\
\text { infolding; they were well } \\
\text { demarcated from the red } \\
\text { facial skin }\end{array}$ \\
\hline Ear length male & & & $3.28 \mathrm{~cm}$ \\
\hline
\end{tabular}




\begin{tabular}{|c|c|c|c|}
\hline $\begin{array}{l}\text { Morphological } \\
\text { traits }\end{array}$ & Cesareo (1950) & Il-Bidwi (1950) & Mallia (1999) \\
\hline $\begin{array}{l}\text { Ear length } \\
\text { female }\end{array}$ & & & $1.88 \mathrm{~cm}$ \\
\hline Ear width male & & & $1.48 \mathrm{~cm}$ \\
\hline $\begin{array}{l}\text { Ear width } \\
\text { female }\end{array}$ & & & $0.77 \mathrm{~cm}$ \\
\hline $\begin{array}{l}\text { Leg shank } \\
\text { colour }\end{array}$ & Black or slate & Black or slate & Slate \\
\hline $\begin{array}{l}\text { Leg feather } \\
\text { cover }\end{array}$ & Featherless & Featherless & Free of feathering \\
\hline Legs & & $\begin{array}{l}\text { Slightly tall with strong but bony } \\
\text { and round shanks. Long straight } \\
\text { toes, kept widely open from one } \\
\text { another }\end{array}$ & \\
\hline Tail angle & 45 degrees & $80^{\circ}-90^{\circ}$ from the back & $\begin{array}{l}\text { Angle of tail with back } \\
\text { ranged from } 70^{\circ} \text { to } 90^{\circ}\end{array}$ \\
\hline Tail length male & & Full tail & $39 \mathrm{~cm}$ \\
\hline $\begin{array}{l}\text { Tail length } \\
\text { female }\end{array}$ & & Firm tail & $15 \mathrm{~cm}$ \\
\hline Egg Colour & White & White & White \\
\hline Egg weight & Average of $2-2.5 \mathrm{oz}$ & & \\
\hline Clutch size & $\begin{array}{l}\text { Up to } 200 \text { eggs } \\
\text { per year }\end{array}$ & & $200-250$ \\
\hline Weight of Male & $2.5-3.2 \mathrm{~kg}$ & Not less than $2.8 \mathrm{~kg}$ & $2.0-2.4 \mathrm{~kg}$ \\
\hline $\begin{array}{l}\text { Weight of } \\
\text { female }\end{array}$ & $2.0-2.7 \mathrm{~kg}$ & Not less than $2.3 \mathrm{~kg}$ & $1.1-1.5 \mathrm{~kg}$ \\
\hline
\end{tabular}

While the two breed descriptions presented in the 1950's complement each other to give a strong indication as to the definition of the breed, the combined description still lacks completeness and is not compatible with the formats usually acceptable in international breed standards of perfection. When these definitions are compared to data published by Mallia (1998), deviation is evident in parameters pertaining to comb, ear lobes, tail and weight, and such drifts have been reported by Aquilina (2012).

In an effort to consolidate the breed standard definition of the Maltese Black, the standards of the other Mediterranean breeds mentioned by Shepard, (1920), Cesareo (1950) and Patrick (1975) and confirmed by Ceccobelli (2013), that have contributed to genetic makeup were consulted to interpret and complete the gaps missing in Table 1 .

\section{Genetic origins}

The genetic link with the Minorcan breed is documented as having been introduced at various stages of the breed stabilisation process. The link with the Andalusian breed is automatic since this breed was developed from the Minorca and originally known as 'Blue Minorcas' (Brown, 1906). It is interesting to note that Brown (1906) discusses that the black variety Minorcas, can be traced back to the Tiverton district to as far back as 1780. Renowned for its exceptional prolificacy and the large size of the eggs, some significant changes were implemented through selection and out-crossing with other breeds. Such alterations were not always beneficial from a production point of view 
but may have contributed to the external characters evolving into a better looking show bird.

The Hamburgh breed has been bred in Britain since early 1700's and a black variety was developed. The breed is well known for its high egg laying capabilities, though the eggs are too small to satisfy market demands. Its prolificacy was capitalised upon by crossing it with other breeds that may not have been as productive, but which produced larger eggs. For this reason many breeders crossed them with the Minorcan and obtained beneficial results. An outstanding feature of the Hamburgh breed is the prominent round ears; this may be the path through which the Maltese Black acquired its round ear, as defined by Cesareo (1950).

The Andalusian breed is assumed to have originated from the Minorcan and was earlier on known as Blue Minorcas. They were first introduced into Britain in 1851. Over time, significant changes have taken place in the type, making it finer. It is a remarkable egg producer both in number and in size, and it is claimed to be superior to the Minorcan. Males were highly sought after for the production of birds known as 'petits poussins'. Brown (1906) commented that the breed was nervous and easily agitated, and such traits were substantiated by Cesareo (1950), Mallia (1999) and Aquilina (2012).

The Leghorn breed was introduced into Britain in the 1870's. Many colours are known together with a black feathered variety with yellow legs that is very hardy and an excellent egg producer. Black Minorcas were crossed with the Black Leghorn to improve egg weight. The Langshan were imported into Britain in 1872. This breed was more renowned for its superior carcass qualities and the dark rich brown tint on the eggshell. It is known to have very poor egg production capacity.

Chronologically speaking, it follows that most probably the first landing of live poultry from Britain in the early 1800's consisted of Black Minorcas and may also have included black Hamburgh and Minorca/Hamburg out-crosses. By the late 1800's the other breeds mentioned above followed and eventually inter-bred to form the bulk of the mongrel flock.

\section{The modern Maltese Black breed}

\section{GENETIC ASPECTS}

According to the genetic origin, the modern Maltese Black breed can be considered as being a composite breed. The breed is critically endangered, with $<50$ breeding adults (as reported by Mallia in 1999) and 96 breeding adults (as reported by Aquilina in 2012). The lack of a Herd Book makes it very difficult to know the exact status of this breed.

A recent survey by Aquilina (2012) examined, in detail, 96 breeding adults belonging to the conservation centre and other private breeders. Effective population size $(\mathrm{Ne})$ for Maltese Black breed was calculated from this survey by means of the formula $\mathrm{Ne}=$ $(4 \mathrm{MF}) /(\mathrm{M}+\mathrm{F})($ Gandini, 2004) was estimated to be 65.6. This estimate can be considered to be the best evaluation since the number of fancy breeders and the number of breeding adults in these small flocks is considered to remain fairly constant.

Preliminary results from ongoing research on Mediterranean chicken breeds (Ceccobelli, 2013) utilising molecular markers (mtDNA and microsatellites) indicate some genetic relationship with the Andalusian and Leghorn breeds, confirming the historical origin of this breed as expressed by Shepard, (1920), Cesareo (1950) and Patrick (1975), and gives scientific support for consulting with these breed standards for the compilation of the Maltese Black breed standard. Most of the animals in this study were included in the haplogroup E, which is widespread in Europe, Middle East and India. The presence of one Maltese Black bird on the haplogroup A could be due to the 
possible genetic contamination with chickens of Chinese origin, as reported by Borg (1933). Additionally, Ceccobelli (2013) observed a deficiency of heterozygosity with an high (0.16724) inbreeding coefficient of the population, confirming the importance of establishing a National Herd Book to structure the breeding scheme, develop pedigree and minimise the incidence of mating between close relatives. The Maltese Black breed, as showed by the Reynolds genetic distance, is closely linked to other Mediterranean chicken breeds (Italian breeds: Ancona, 0.24; White Leghorn, 0.21; Romagnola, 0.23; Valdarnese, 0.21; Spanish breeds, Pita Pinta Asturiana, 0.19; Gallina de Sobrarbe, 0.18; Albanian population, 0.14) and a Serbian breed (Banat Nacked Neck; 0.18). Structure analysis showed a genetic mixture in the Maltese Black of Italian and Spanish breeds suggesting the possible genetic relationship between them.

\section{PRODUCTIVE PERFORMANCE}

The main phenotypic characteristics of the population evaluated by Aquilina in 2012 are showed in Table 2. Results indicate that while some phenotypical traits are according to standards, others show a significant drift away. Significant deviations are evident in traits pertaining to comb serration, ear lobes, tail and live weight (Table 3). The live weights of the current Maltese Black population are $1.76+0.29 \mathrm{~kg}$ and $1.39+0.22 \mathrm{~kg}$ for cocks and hens respectively, which is too small a body frame to fulfil its original intention as a dual purpose breed.

Table 2 Main phenotypic traits of Maltese Black chicks (expressed as \%)*.

\begin{tabular}{llll}
\hline & & Female & Male \\
\hline Feather Type & Normal & & 100.0 \\
Feather Distribution & Normal & 96.0 & 100.0 \\
Feather Colour & Black \& Green sheen & 96.0 & 97.9 \\
Under Feathers Colour & Other & 94.0 & 2.1 \\
Skin Colour & Black & 2.0 & 100.0 \\
Shanks Colour & White & 96.0 & 100.0 \\
& Black & 96.0 & 10.4 \\
Beak Colour & Other & 10.0 & 87.5 \\
& Slate and Horn & 84.0 & 2.1 \\
Comb and Wattle Colour & Other & 2.0 & 44.8 \\
Ear-Lobe Colour & Red & 43.0 & 55.2 \\
& White & 53.0 & 100.0 \\
Eye Type and Colour & White and Red & 96.0 & 71.9 \\
& Other & 69.0 & 25.0 \\
Ear-Lobe Type & Large, amber \& prominent & 24.0 & 3.1 \\
& Other & 3.0 & 99.0 \\
& Round and smooth & 95.0 & 1.0 \\
& Round and not smooth & 1.0 & 25.0 \\
Comb serration & Not round and smooth & 24.0 & 5.2 \\
& Not round and not smooth & 5.0 & 56.3 \\
& Less than 5 & 54.0 & 13.5 \\
& Breed standard 5 & 9.05 & 18.07 \\
& More than 5 & 47.6 & 46.7 \\
& & 42.8 & 34.7 \\
\hline
\end{tabular}

*: modified from Aquilina (2012).

The Maltese Black was developed as a rustic breed to produce eggs and chicken meat for rural families. Most breeders today claim that the breed is capable of producing $205 \pm$ 15 eggs per year which could be somewhat smaller in weight than the ones normally available as table eggs $(50 \pm 5 \mathrm{~g})$. All breeders confirmed that the egg shell is white, and 
different shades of whites are also possible. Growth rate is similar to very slow-growing lines with a mean weight at 12 weeks of $1.3 \pm 0.1 \mathrm{~kg}$. All breeders claim that hatching usually shows a $75 \%$ rate in favour of male chicks. This phenomena needs to be explored further as it may have significant economic implications especially in the light that traditionally males were castrated and reared up as capons (Griffiths, 1803) to supply high quality meat.

\section{THE NEW BREED STANDARD}

In efforts to complete the breed standard definition of the Maltese Black, the standards of the other related Mediterranean breeds as defined in the American Standards of Perfection (American Poultry Association, 1998) were consulted to interpret, describe and complete the missing information in Table 1. The results of this exercise are presented in Table 3 and follow the format adopted by the American Standards of Perfection.

Table 3 Breed Standards for the Maltese Black chicken.

\begin{tabular}{|c|c|}
\hline \multicolumn{2}{|l|}{ MALTESE BLACK } \\
\hline Economic & A nervous and hardy dual purpose non-sitting chicken, noted for the production of \\
\hline Qualities & large (56-70 grams) chalk-white eggs; colour of skin white \\
\hline Disqualifications & $\begin{array}{l}\text { Red in ear-lobes, covering more than one-third of surface; red, yellow or positive white } \\
\text { in plumage; shanks other than black or slate and featherless, combs that are beefy or } \\
\text { loped in cocks; White toe nails }\end{array}$ \\
\hline Standard Weights & Pullet: $2.0 \mathrm{~kg} \quad$ Hen: $2.0-2.7 \mathrm{~kg}$ \\
\hline & Cock: $2.5-3.2 \mathrm{~kg}$ \\
\hline \multicolumn{2}{|l|}{ SHAPE MALE } \\
\hline Posture & Tall, busy and proud \\
\hline Comb & $\begin{array}{l}\text { Single; medium in size, smooth, straight and upright, firm and even on head, frontend } \\
\text { does not exceed the beak; evenly and deeply serrated, having five well-defined points } \\
\text { being wide at the bottom and tapering towards the top, blade following slightly the } \\
\text { curve of the neck without touching the head. Free from twists folds or excrescences }\end{array}$ \\
\hline Beak & $\begin{array}{l}\text { Medium length, strong, nicely curved, slate and horn in colour. Top beak overlapping } \\
\text { bottom }\end{array}$ \\
\hline Face & Full and smooth, fine in texture, free from wrinkles \\
\hline Eyes & Large, prominent and amber red in colour \\
\hline Wattles & $\begin{array}{l}\text { Long and thin and fine in texture, well rounded smooth and free from folds and } \\
\text { wrinkles }\end{array}$ \\
\hline Ear-Lobes & Large ears, round, smooth, white and free from folds, fitting close to head \\
\hline Head & Moderately long and deep, inclined to be flat on top. Smooth fine proportions \\
\hline Neck & Rather long, well-arched, with abundant hackle flowing well over shoulders \\
\hline Back & $\begin{array}{l}\text { Wide on the shoulders with a rather long back sloping towards the tail, moderately } \\
\text { broad its entire length, high at shoulders, sloping slightly to tail } \\
\text { Saddle Feathers -- long and abundant }\end{array}$ \\
\hline \multirow[t]{4}{*}{ Tail } & $\begin{array}{l}\text { Large and full well spread, carried at an angle of } 45 \text { degrees above horizontal, ( } 80 \text { to } 90 \\
\text { degrees with the slope of the back) }\end{array}$ \\
\hline & Main Tail Feathers -- broad and overlapping \\
\hline & Sickles - long, even, well curved \\
\hline & Coverts - abundant \\
\hline \multirow[t]{2}{*}{ Wings } & Large, well-folded, carried without drooping held close to the body \\
\hline & $\begin{array}{l}\text { Primaries and Secondaries - broad and overlapping in natural order when wing is } \\
\text { folded }\end{array}$ \\
\hline Breast & $\begin{array}{l}\text { Broad/wide, deep, well-rounded, carried well up and forward, straight keel or } \\
\text { breast-bone }\end{array}$ \\
\hline Body \& Fluff & Body -- long, well-rounded, slightly broader at front than rear \\
\hline Legs \& Toes & Tall on legs. Legs set well apart, straig \\
\hline & Lower Thighs - medium size, rather long: hock joints showing \\
\hline
\end{tabular}


Table 3 Continued

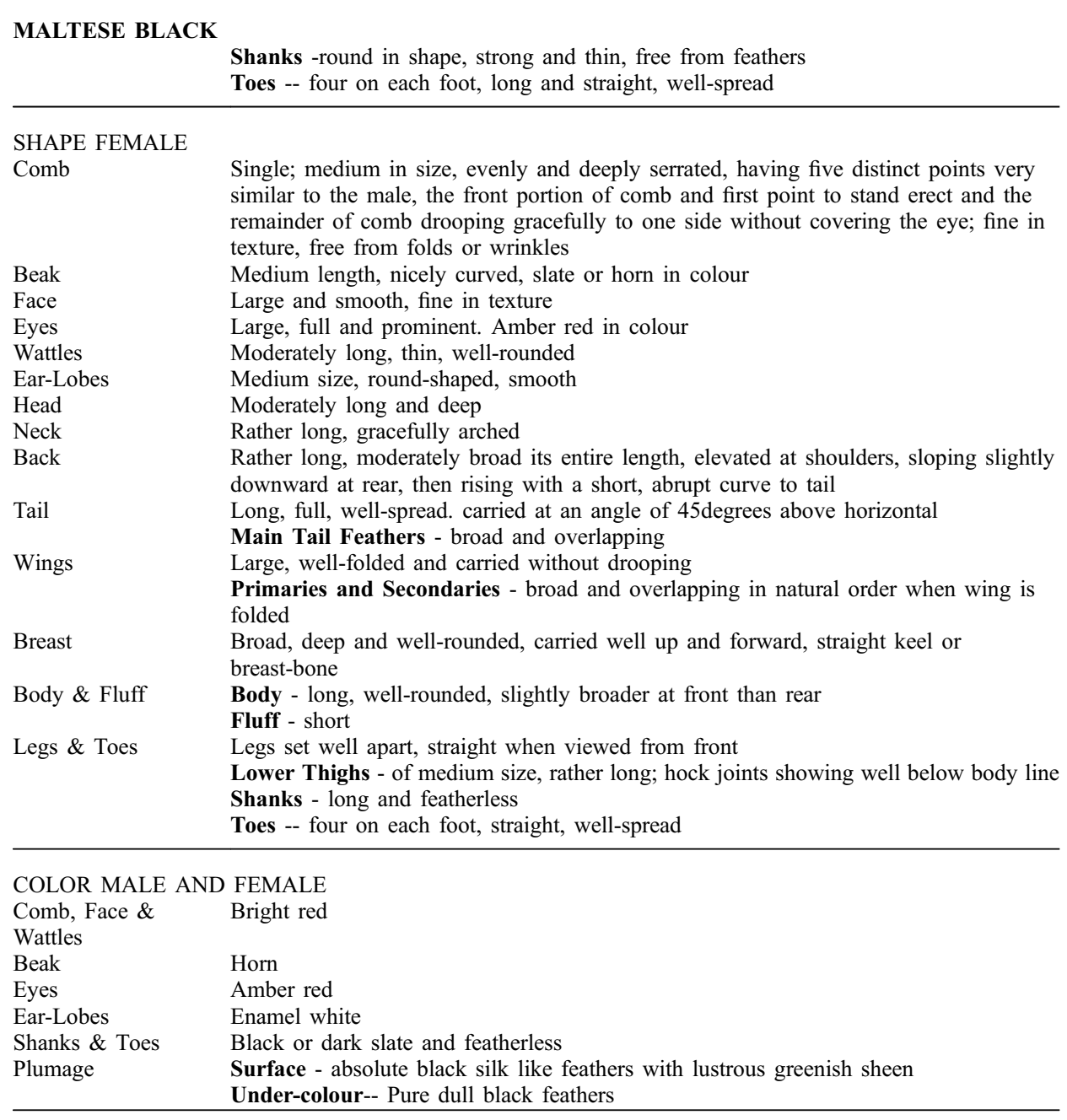

On completion of the standard, the parameters were given to a professional artist to give a visual phenotypic interpretation of the breed standard (Figure 1). 


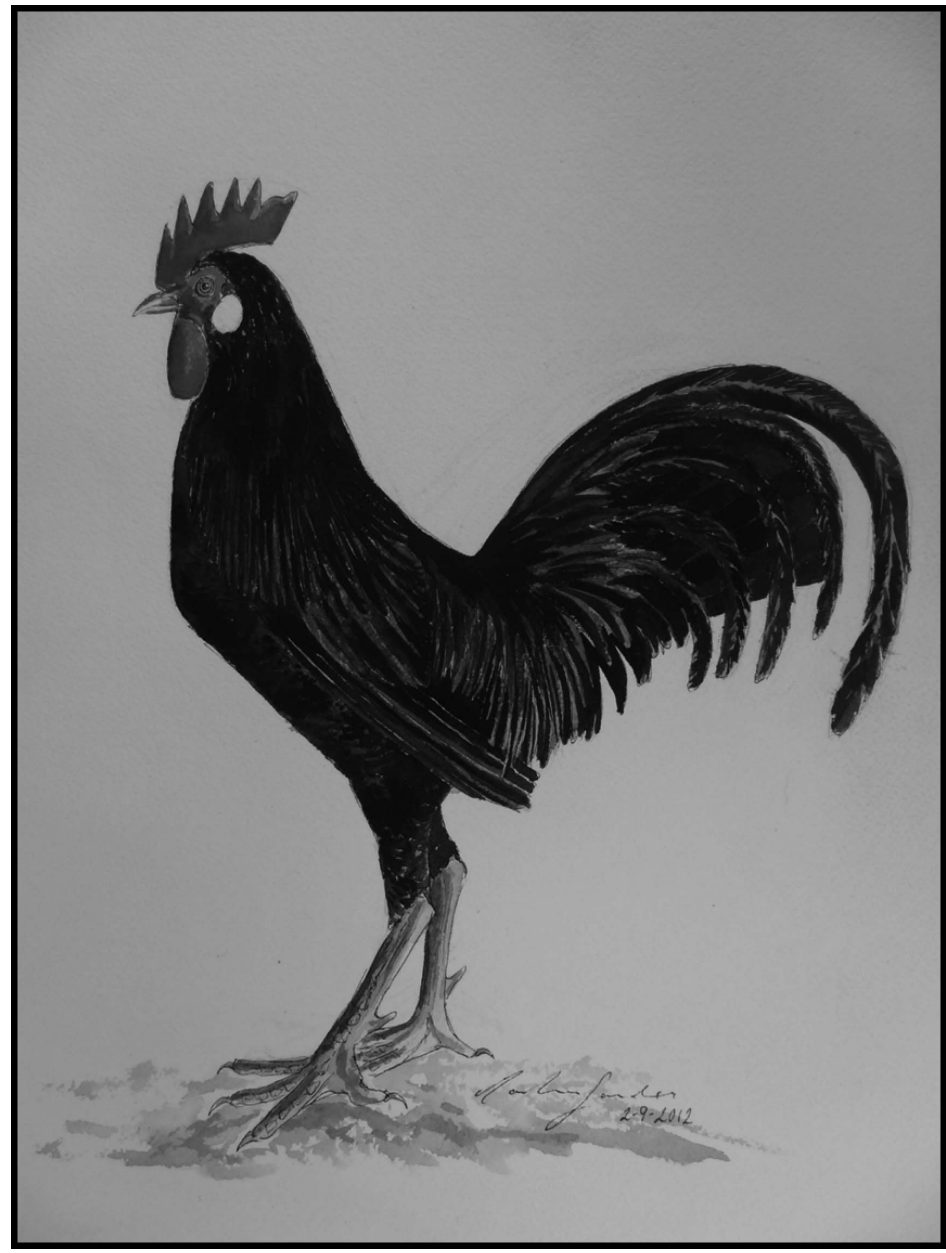

Figure 1 Artistic interpretation of the complete Maltese Black breed standard (Gouder, 2012).

\section{Conclusions}

The present Maltese Black population has drifted away from the original standard, and in doing so, has lost its rustic capacity. There is an urgent need to implement an appropriate breeding program focusing on 1) the recuperation of this genetic pool, 2) appropriate mating schemes to breed back to standard while minimising inbreeding, and 3) the setting up of a herd book to catalogue pedigree.

The breed standard as presented in this study should be circulated amongst all local poultry clubs to bring awareness to amateur breeders and guide them in selection programs. The updated standards will not only act as the standard against which all future breeding programs are directed, but also as guidelines for judges involved in poultry shows. Once re-established, the dual purpose nature of this breed will once again occupy its niche within the Maltese agro-environment and compliment the national agricultural patrimony and heritage. 


\section{References}

AMERICAN POULTRY ASSOCIATION (1998) The American Standards of Perfection, California, Global Interprint.

ANDERSON, A. (1802) A Journal of the Forces which Sailed from the Downs. Published: J. Debrett.

AQUILINA, P. (2012) Dissertation for Bachelor of Science in Mediterranean Agro-Ecosystems Management 'Descriptors of the indigenous Maltese breed of chicken: the Maltese Black'. University of Perugia/University of Malta.

AZZOPARDI, A. (1933) It-Tigieg. Melita Agricola. Malta: Government of Malta.

BORG, J. (1933) It-Tigieg Maltin. Melita Agricola. Malta February 1933: Government of Malta.

BROCKMAN, E. (1961) Last Bastion: Sketches of the Maltese Islands, United Kingdom, Darton, Longman and Todd.

BROWN, E. (1906) Races of domestic poultry. Edward Arnold, London.

CECCOBELLI, S. (2013) Genetic diversity of Mediterranean autochthonous chicken breeds. PhD dissertation, University of Padova.

CESAREO, J. (1950) The Maltese Black Breed. World's Poultry Science Journal 6: 277-278.

CORNELL, S. S. (1857) Cornell High School Geography. New York: D. Appleton and Company.

COUNCIL REGULATION (EC) No 1804/99 of July 1999 supplementing Regulation (EEC) No 2092/91 on organic production of agricultural products. Off. J., L 222, 24/08/1999, pp 1-28.

GANDINI, G. (2004) Piccole popolazioni e loro salvaguardia genetica, in: Pagnacco, G. 'Genetica Animale Applicata', casa Editrice Ambrosiana, Milano, pp 291-308.

GOUDER, M. (2012) Artistic interpretation of the complete Maltese Black breed standard. Malta.

GOVERNMENT DEPARTMENTS REPORT (1933-1934) Department of Agriculture. Malta.

GRIFFITHS, G. E. (1803) The Monthly Review 41: 84.

IL-BIDWI (1950) Tigieg Suwed Maltin. Il-Bidwi. Malta: Government of Malta.

IRELAND H WILLIAM (1828) The life of Napoleon Bonaparte: in four volumes, Vol. 2, pp 352.

MALLIA, J.G. (1998) The Black Maltese: a Mediterranean, light breed of poultry. Animal Genetic Resource Information 24: 41-48.

MALLIA, J.G. (1999) In-situ conservation of the Black Maltese and performance evaluation under small-scale intensive system. First INFPD / FAO electric conference on family poultry. Available at: http://www.fao.org/ ag/againfo/subjects/en/infpd/documents/econf_scope/add_paper8.html.

PATRICK, D.A. (1975) The Poultry Industry in Malta from the fifties to the seventies. B.A. (General), University of Malta.

POULTRY DIGEST (1951) New Breed Developed, Vol. 10, pp 166.

SHEPARD, D.J. (1920) Report on Agriculture in Malta. Malta: Government of Malta.

UNITED NATIONS FOOD AND AGRICULTURE ORGANIZATION. FAO UNITED NATIONS (2009) Available at: http://www.fao.org/.

UNIVERSITY OF HAWAII (1945) Agricultural Experiment Station. Issues 95-107: pp 112 Hawaii Agricultural Experiment Station, United States. Office of Experiment Stations. 
396 World's Poultry Science Journal, Vol. 70, June 2014 